\title{
Imperceptible Scar over Face and Neck: A New Aesthetic Modification of Parotid Incision
}

\author{
Gangadhara KS, ${ }^{1}$ Hamsa Shetty, ${ }^{1}$ Sridhara $S^{1}$
}

\begin{abstract}
Introduction
The mainstay of treatment for parotid tumours is surgery. Since the incision site involves visible areas of head and neck several modifications have evolved since its first description in 1912 by Blair and all the subsequent incisions have more or less aimed at giving better aesthesis in terms of post-operative facial scar. We describe a modification of earlier incisions for parotidectomy, which aims at camouflaging the post-operative facial and neck scar. Materials And Methods

Fourteen patients were included in this study, who presented with parotid tumours and underwent either superficial or total parotidectomy. The modified incision was used in all the patients and various parameters were recorded (intra operatively as well as post operatively during the follow up visits, upto lyear) including post-operative scar visibility and patient satisfaction in terms of aesthetic appeal.

Results

All the 14 patients reported highly satisfied in terms of post-operative aesthetic outcome. There was no intra operative limitation of exposure by using this modified incision and neither any significant post-operative complication was encountered.

Conclusion

Our attempt at evolving an aesthetically modified incision for parotidectomy with no facial or neck scar post-operatively was achieved, along with certain more extended benefits of using this innovative incision.

$\underline{\text { Keywords }}$

Parotid Neoplasms; Surgical Incision; Esthetics
\end{abstract}

$\underline{\text { ABSTRACT }}$

B oth benign and malignant tumours of the parotid are commonly encountered in clinical practice and pleomorphic adenoma accounts for $70 \%$ of parotid tumours. ${ }^{1}$ Since surgery is the mainstay of treatment of parotid tumours, several modifications of the parotid incisions have evolved over the decades ever since the first description of the parotid incision was described by Blair in 1912 and modified by Bailey in 1941. ${ }^{2}$ All the subsequent modifications have more or less aimed at reducing the post-operative facial scar and thus better aesthetic outcome.

\section{1 - Department of ENT, SIMS, Shimoga, Karnataka}

\section{Corresponding author:}

Dr Hamsa Shetty

email: hamsa.shetty@rediffmail.com
However none of the incisions described in literature has aimed at completely camouflaging the facial scar, which prompted us to modify the incision to the next level, leaving behind a completely scarless area over the face while at the same time enabling adequate exposure and delivery of the tumour, along with preservation of the facial nerve with all its branches.

\section{Materials and Methods}

All those patients who presented with parotid swelling to the ENT OPD between January 2017 to January 2019 and FNAC was suggestive of parotid tumour (both benign and malignant) and subsequently underwent either superficial or total parotidectomy under General anaesthesia were included in the study. A total 14 patients (male 6 and female 8 ) aged between 18-70yrs 
Table I: Diagnoses of the parotid swellings

\begin{tabular}{|c|c|c|c|}
\hline SERIAL NO. & AGE (YEARS) & SEX & DIAGNOSIS \\
\hline 1 & 38 & $\mathbf{M}$ & Pleomorphic adenoma, Right parotid \\
\hline 2 & 55 & $\mathbf{F}$ & Pleomorphic adenoma, Left parotid \\
\hline 3 & 28 & $\mathbf{F}$ & Pleomorphic adenoma, Left parotid \\
\hline 4 & 25 & M & Pleomorphic adenoma, Right parotid \\
\hline 5 & 27 & $\mathbf{F}$ & Pleomorphic adenoma, Left parotid \\
\hline 6 & 27 & $\mathbf{M}$ & Pleomorphic adenoma, Right parotid \\
\hline 7 & 18 & M & Pleomorphic adenoma, Left parotid \\
\hline 8 & 48 & $\mathbf{M}$ & Pleomorphic adenoma, Right parotid \\
\hline 9 & 70 & $\mathbf{F}$ & Epidermal cyst, Left parotid \\
\hline 10 & 44 & $\mathbf{F}$ & $\begin{array}{l}\text { FNAC-Retention cyst, Left parotid } \\
\text { HPE-Mucoepidermoid carcinoma }\end{array}$ \\
\hline 11 & 36 & $\mathbf{F}$ & Pleomorphic adenoma, Left parotid \\
\hline 12 & 42 & $\mathbf{M}$ & Pleomorphic adenoma, Right parotid \\
\hline 13 & 25 & $\mathbf{F}$ & Pleomorphic adenoma, Left parotid \\
\hline 14 & 54 & $\mathbf{F}$ & Pleomorphic adenoma, Right parotid \\
\hline
\end{tabular}

were included in the study. (Table I)

Out of the 14 patients, in 12 patients $(85.71 \%)$ histopathology corroborated the FNAC diagnosis of pleomorphic adenoma and 1 patient (7.14\%) was diagnosed as epidermal cyst while in another patient (7.14\%) FNAC was suggestive of retention cyst but post operative histopathological examination reported mucoepidermoid carcinoma.

In all the 14 patients we used our aesthetically modified incision described as follows: This incision begins just in front of the root of helix, extending downwards over the free edge of tragus and curving backwards behind the lobule towards the mastoid tip and extending along the occipital hairline. (Fig.1a and 1b).This leaves no visible scar on the face and the posterior limb of the incision is well hidden behind the pinna and under the hair. There was no limitation in tumour exposure and its delivery and neither any difficulty was encountered in exposing the facial nerve with all its branches.

Ten patients were followed up post operatively at 1 month, 6 months and 1yr. Four patients were followed up at 1 month and 6months and will be followed up at $1 \mathrm{yr}$ as well. We focussed primarily on assessing the post-operative scar visibility and patient satisfaction in terms of aesthetic appearance at the incision site.

Other complications like wound dehiscence, skin 


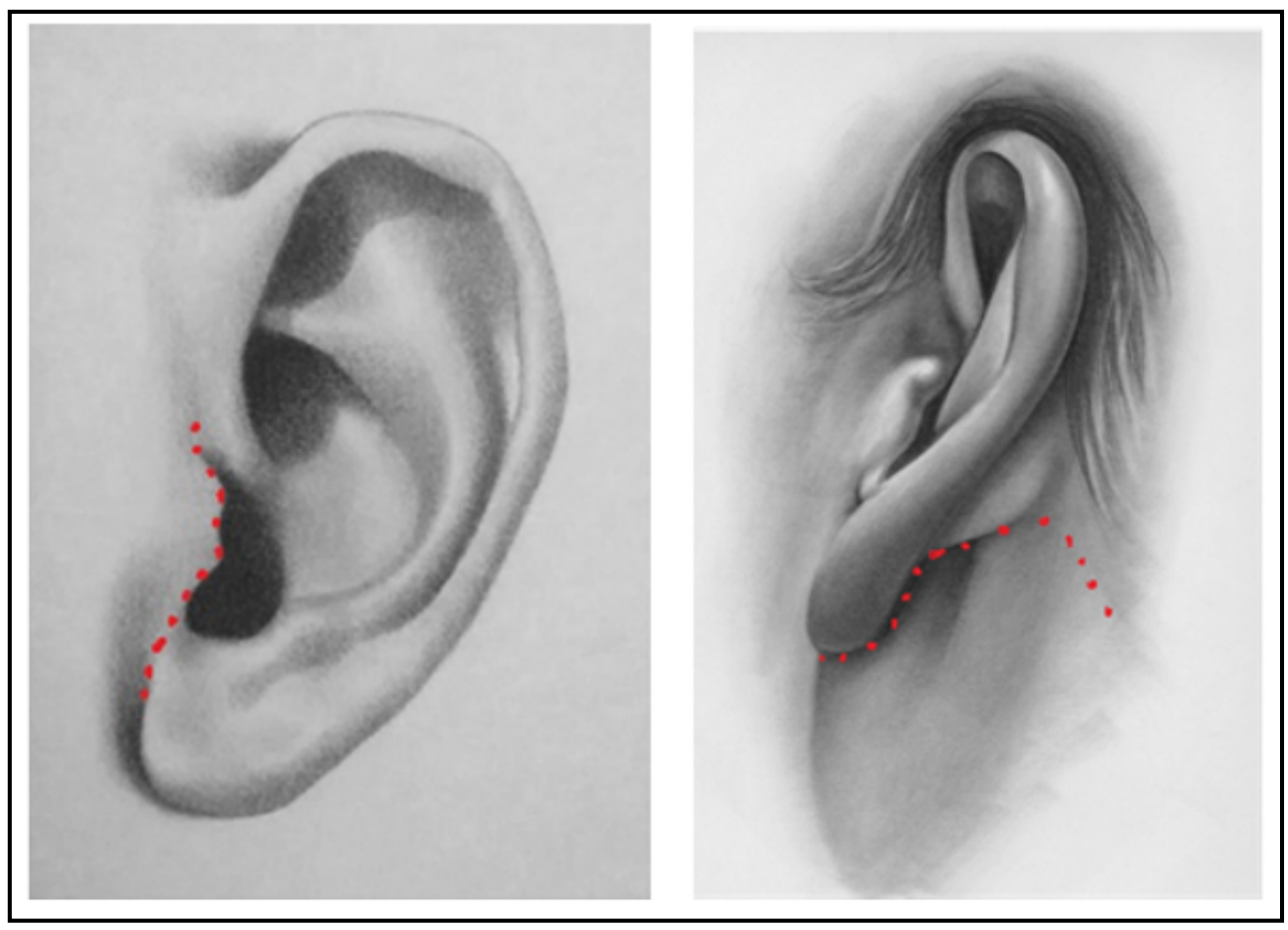

Fig.1a. Modification described in our study (source-authors own depiction of incision on artist pictures)

darkening, serous collection were also recorded.

\section{Results}

All the 14 patients had near imperceptible scar over the free edge of tragus and absolutely no facial scar, at 6 months and 1yr follow up. (Figs. 2a \& 2b) Thus a very high satisfaction was reported by the patients. In a 5 step Patient satisfaction Scale ranging from dissatisfied to very satisfied, all the 14 patients reported very satisfied.

Other complications: Post operatively at 1 week follow up, 2 patients had darkening of skin in the post auricular region which healed well at 1 month follow up. One patient had serous collection at the post auricular region which was drained with a satisfactory healing of incision site. One patient who underwent superficial parotidectomy for retention cyst, the histopathological examination revealed mucoepidermoid carcinoma, hence total parotidectomy was done following which she developed grade 2 House Brackman facial weakness which recovered completely over 3 months.

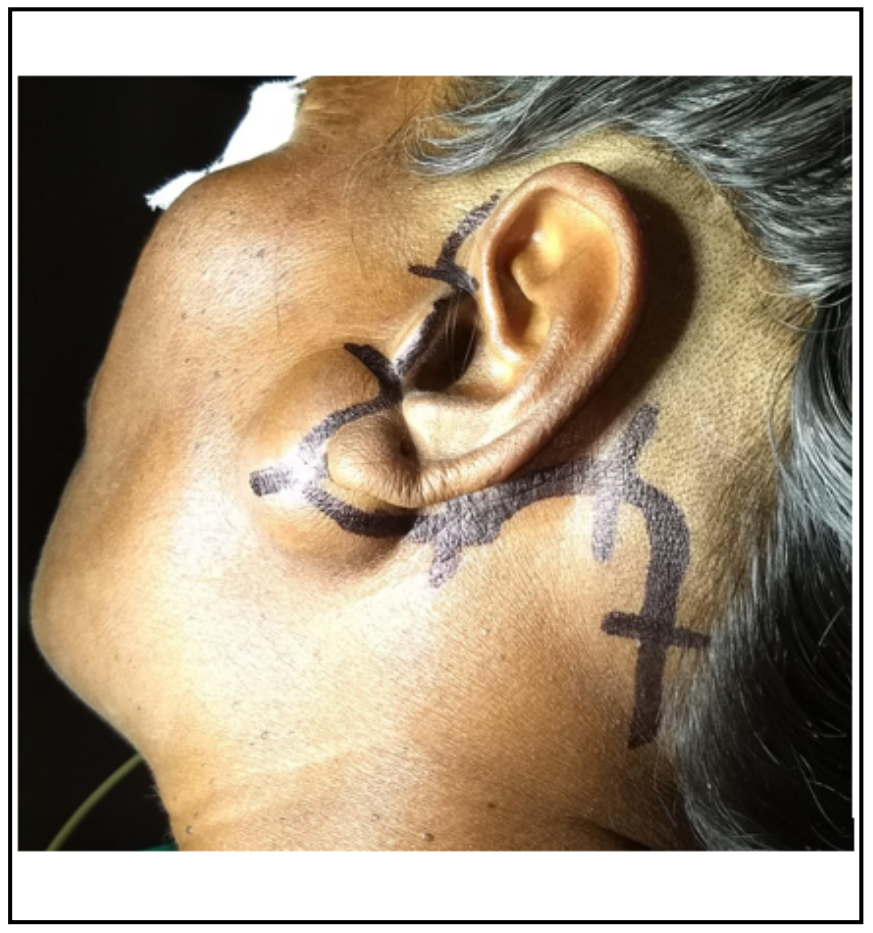

Fig. 1b. The incision line 


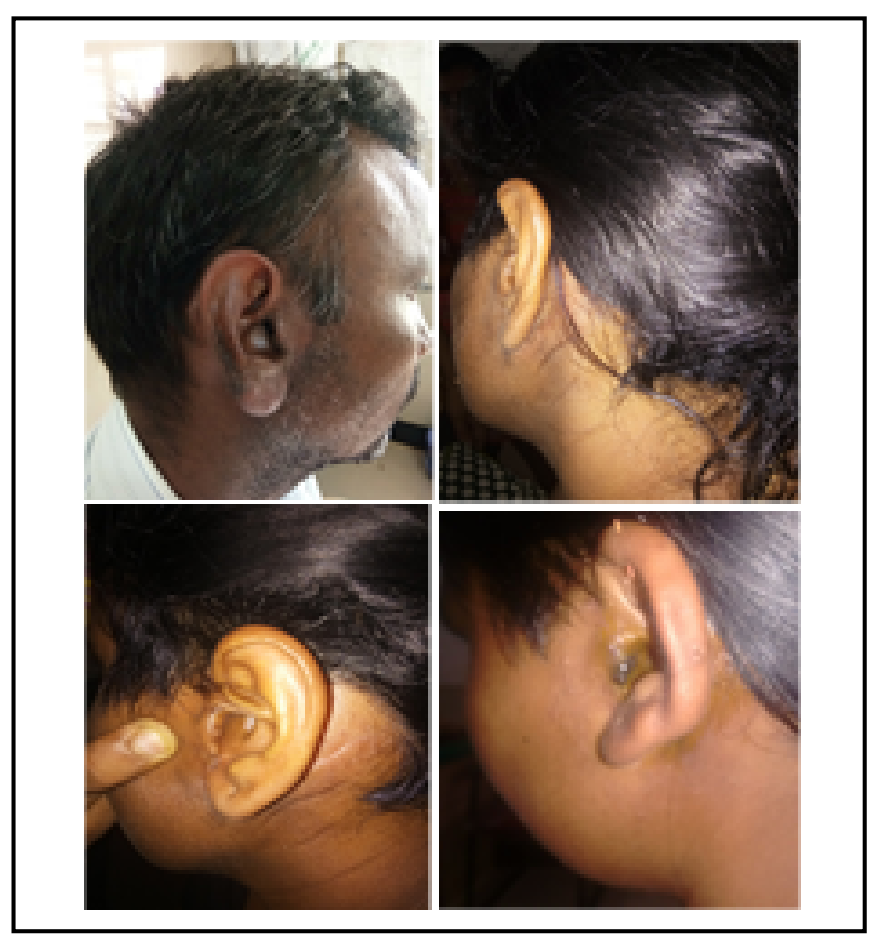

Fig. 2a. Post-operative results -completely camouflaged scar with excellent aesthesis.

Yet another patient operated for pleomorphic adenoma had post-operative grade 3 facial palsy which completely recovered to grade 0 at 3 months follow up.

\section{Discussion}

Currently modified Blair incision is the most popular and widely used incision for parotidectomy.,2,4 This incision leaves a visible scar in front of the tragus and in the neck. (Fig. 3)

The facelift incision gained popularity after Appiani \& Delfino reported its use in their study. ${ }^{4}$ In this incision though neck scar is avoided, a visible scar in front of the ear is inevitable. (Fig. 4)

Retro-auricular hairline (RAHI) incision has no scar either in front of tragus or over it, as it is completely retro-auricular.(Fig. 5) This becomes a huge limitation when the tumour is lying in front of tragus (which is a common scenario), as it is impossible to achieve tumour exposure without an anterior incision in these cases. ${ }^{5}$

In another incision described by Panda et al, the

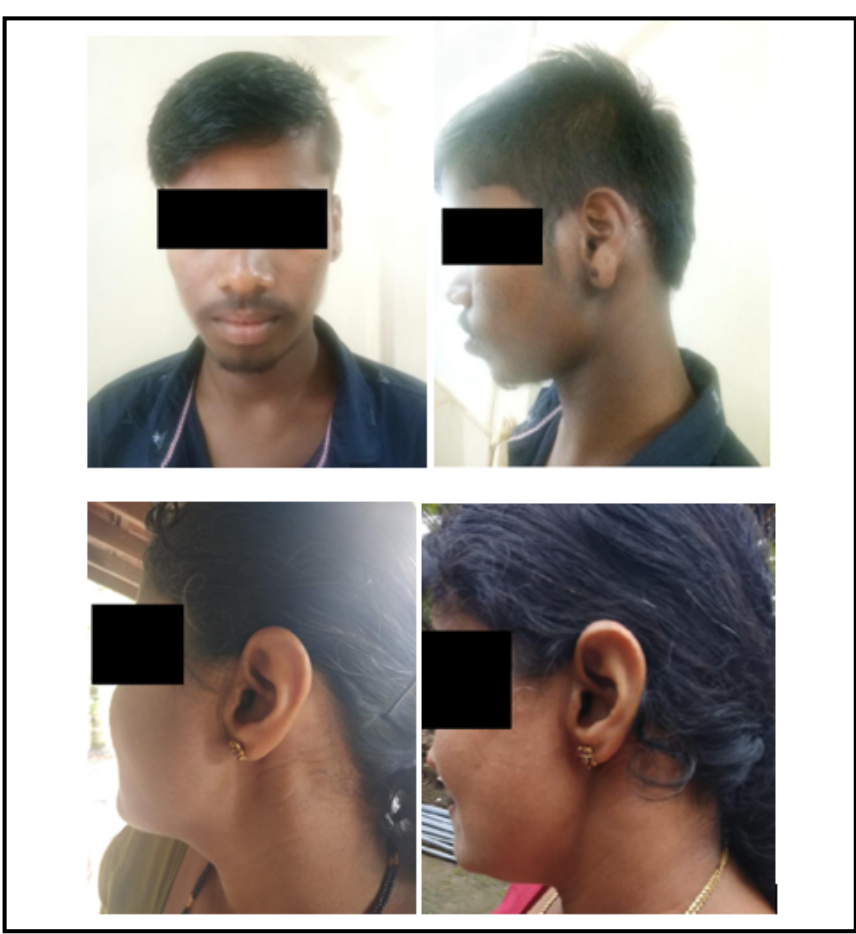

Fig.2b. Post-operative completely camouflaged scar at 1 year follow up.

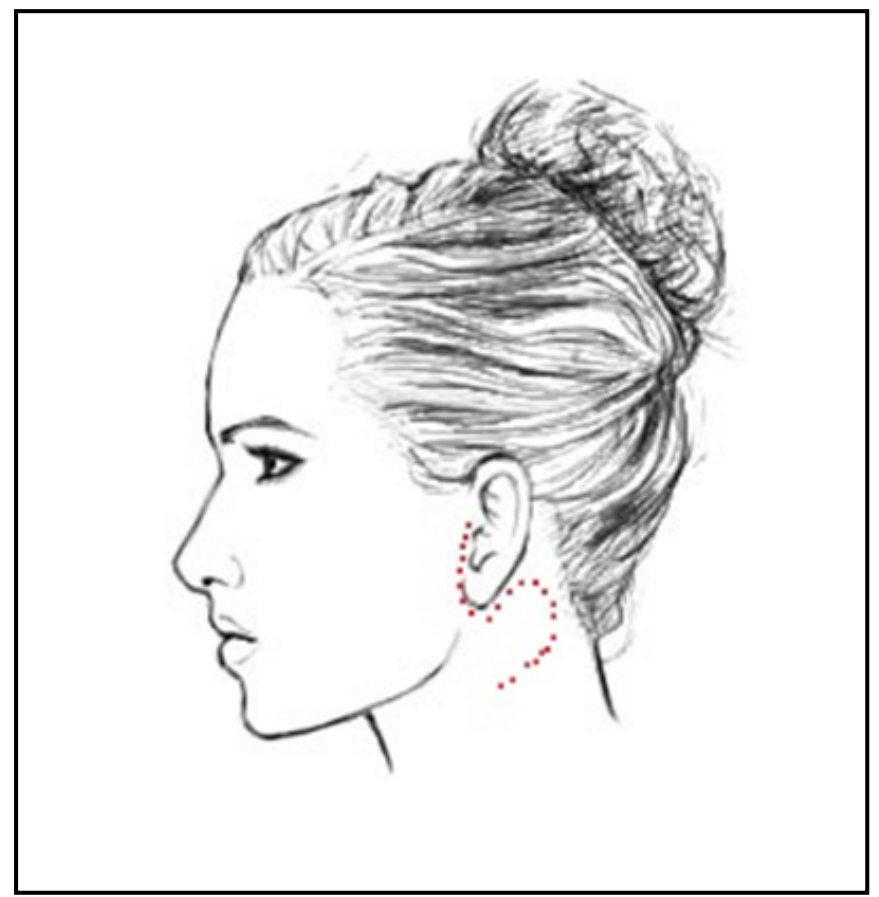

Fig. 3. Modified Blair's incision(Source: Bailey H.The tumours of the parotid gland with special reference to total parotidectomy. Br J Surg. 1941; 28:337-46) 


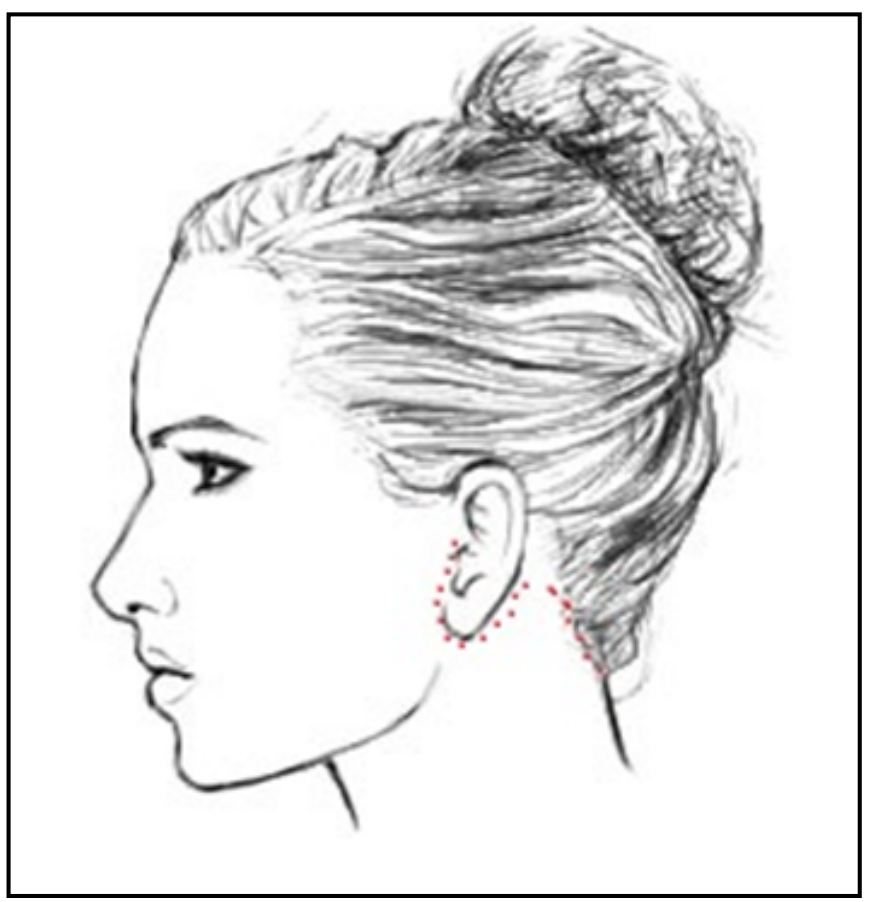

Fig. 4. Facelift Incision (Source: Appiani E,Delfino MC. Plastic incisions for facial and neck tumors. Ann Plast Surg.1984; 13:335-52)

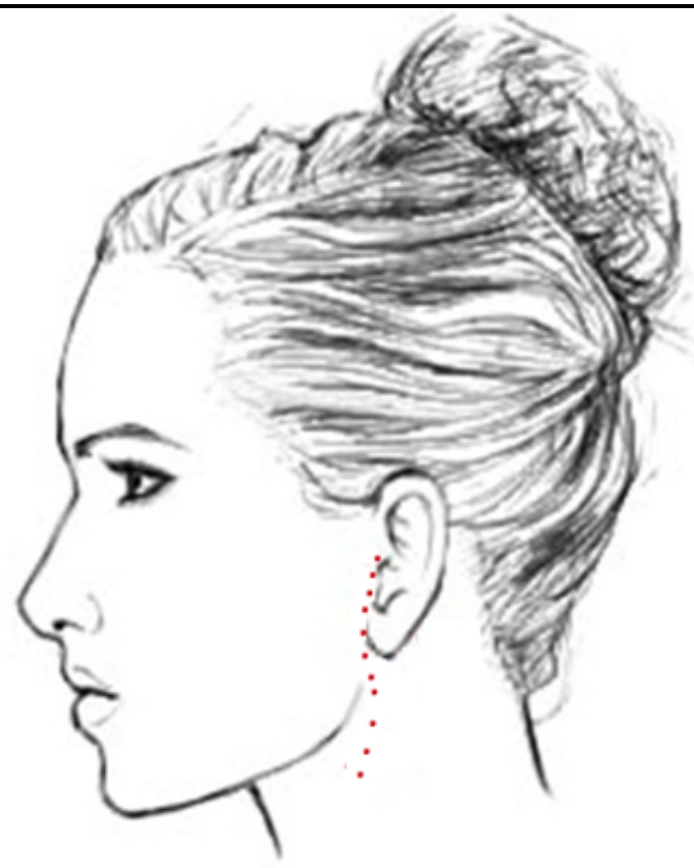

Fig. 6. Incision described by Dr Panda (Source: Panda NK, Kaushal D, Verma R. Do we need to modify the parotidectomy incision? Indian J Otolaryngol Head and Neck Surg. 2016; 68:487-9)

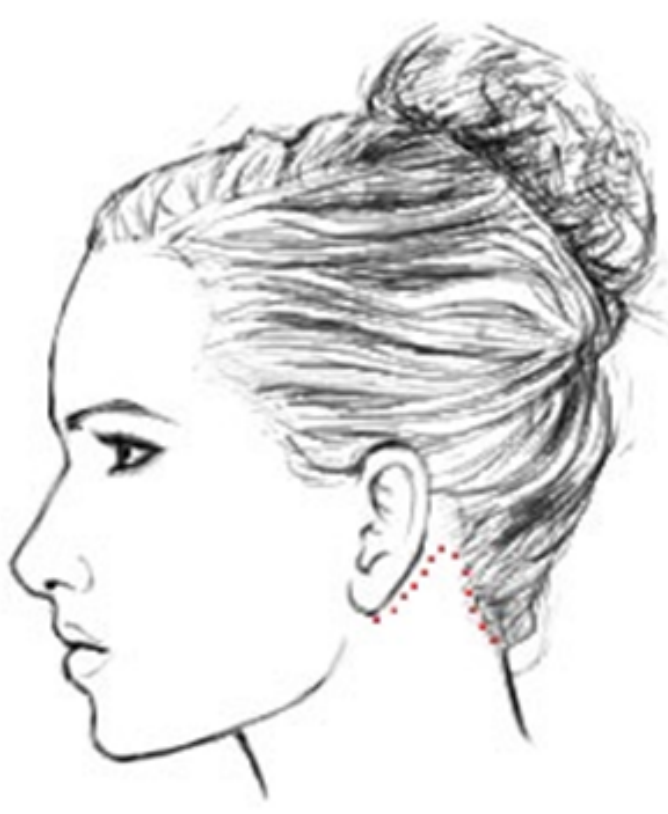

Fig. 5. Retroauricular hairline incision(RAHI) (Source: Roh JL.Extracapsular dissection of benign parotid tumor using a retroauricular hairline incision approach.Am J Surg. 2009; 197:e53-6)

incision extends down in front of the tragus with the vertical limb extending on to the neck without curving backwards, leaving a visible facial scar. ${ }^{6}$ (Fig. 6)

The only incision which is closest to our modification is the one described by Shah et al, in which the incision is over the free edge of tragus but after curving backwards again descends down on to the neck leaving a visible cervical scar. ${ }^{7}$ (Fig. 7)

The incision described in our study leaves no visible scar either on the face or on the neck and does not compromise surgical exposure of the tumour. (Fig. 8) Neither was there any difficulty in locating and exposing the facial nerve. (Fig. 9) No significant post-operative complication was reported in any of the patients. To the best of our knowledge this modification evolved by us is not described in the literature hence we named the incision as Gangadhara and Sridhar's incision.

\section{Extended benefits of using this incision:}

This incision can also be used for accessing the 


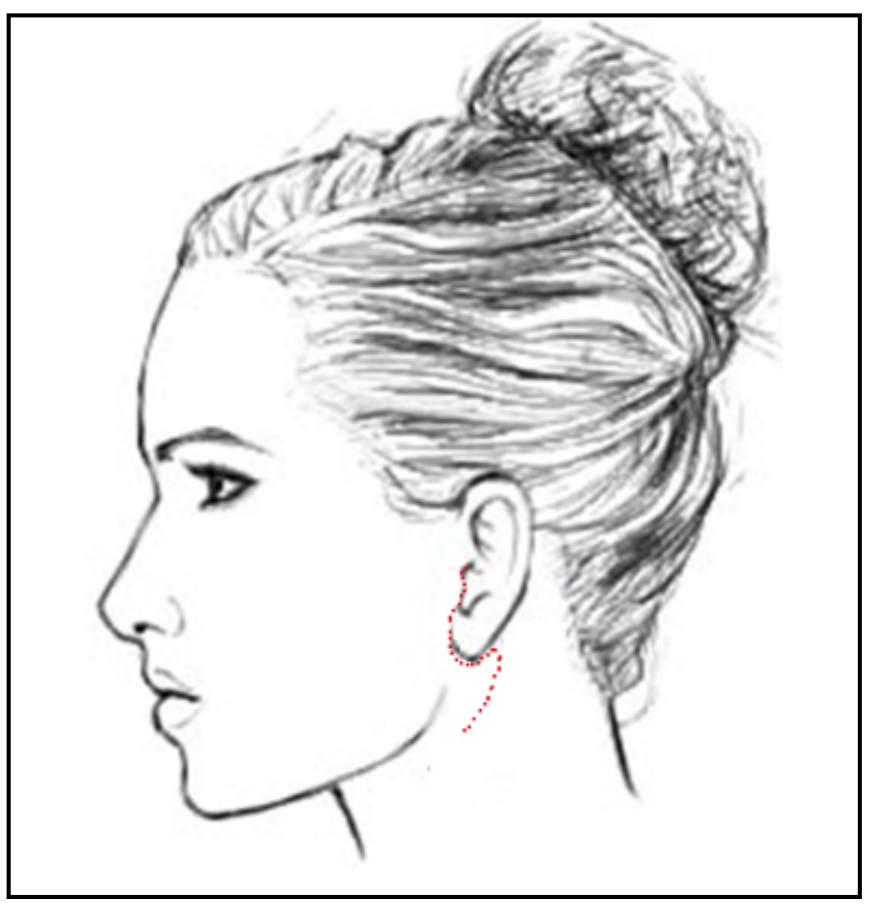

Fig. 7. Modification described by Dr Jatin Shah (Source: Shah J, Patel S, Singh B. Jatin Shah's Head and Neck Surgery and Oncology. 4th ed Mosby Elsevier. Salivary glands13:544-7)

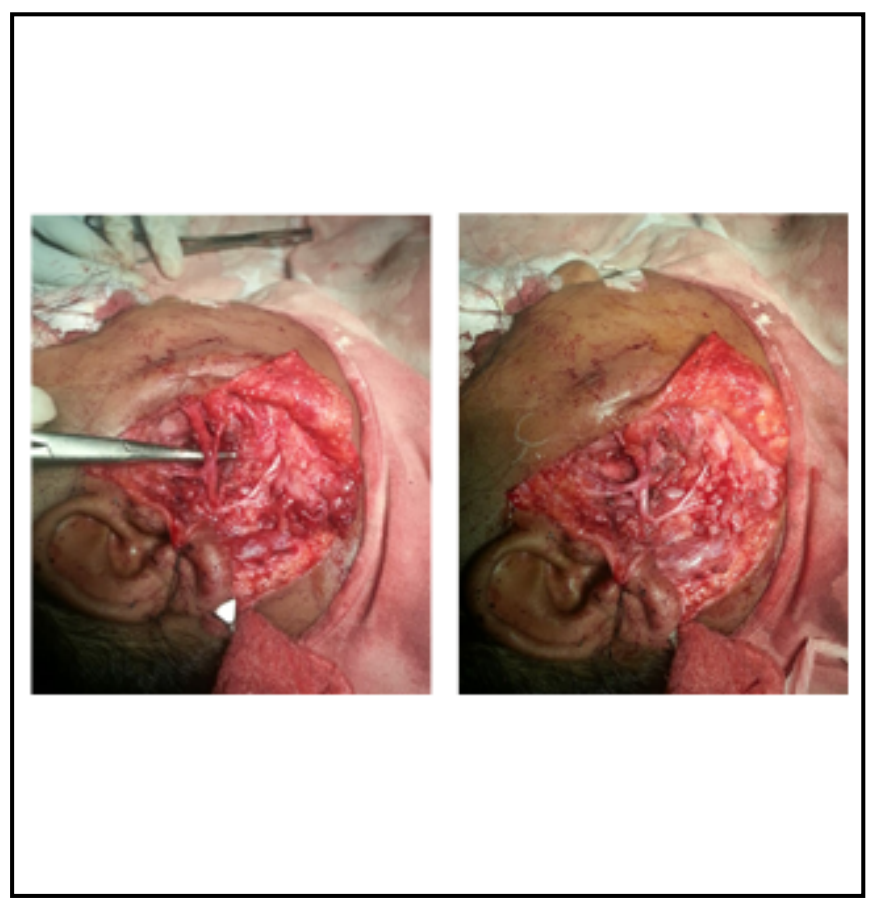

Fig. 9. Facial nerve exposure with all its branches after superficial parotidectomy using our modification

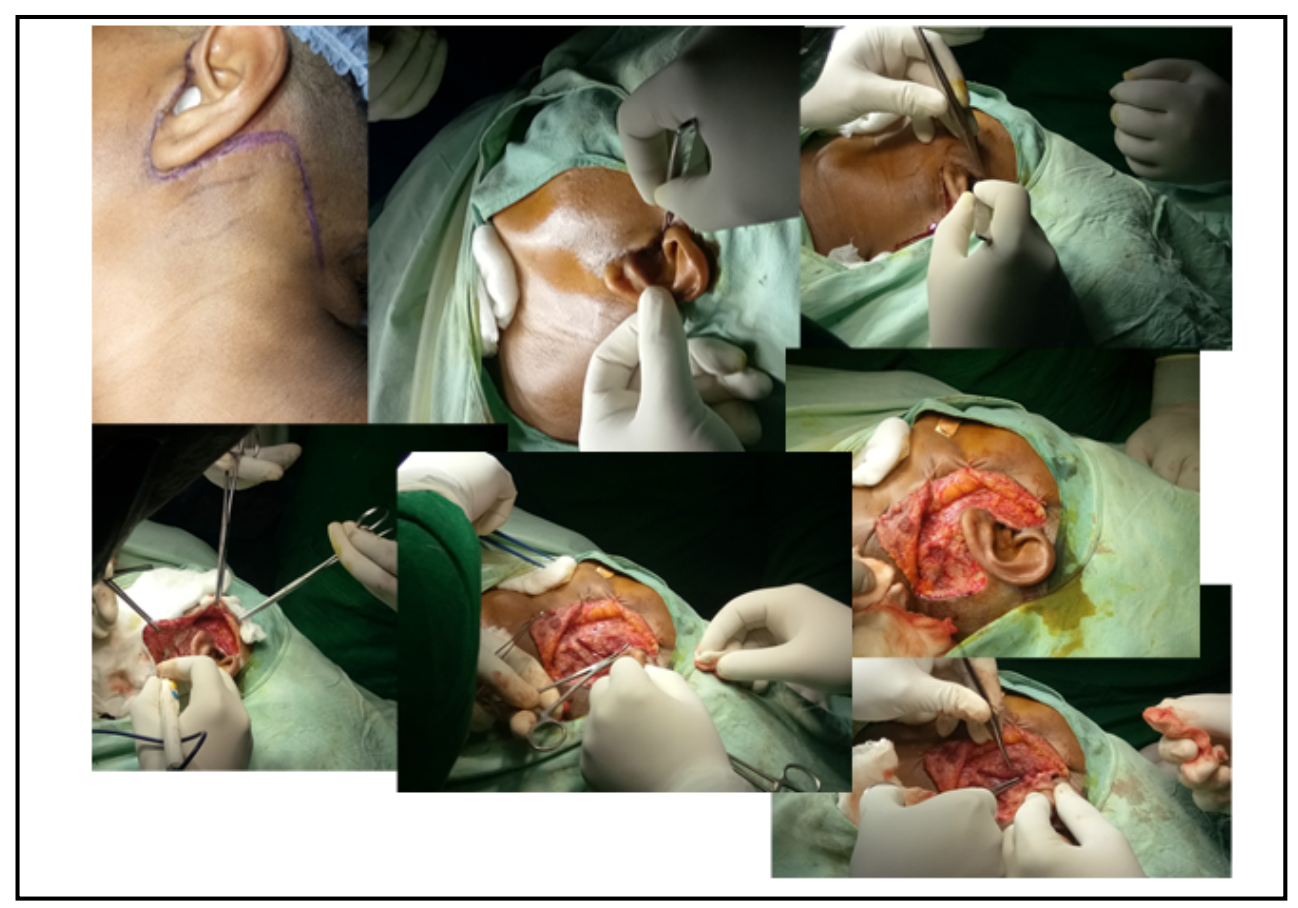

Fig. 8. Modification described in our study 
mandibular condyle for fracture reduction procedures which otherwise routinely employs Alkayat Bramley incision (which leaves a visible scar in front of the ear). ${ }^{3}$

We would also like to highlight that if the tumour is low lying and not involving the area in front of the tragus the superior part of the incision can be completely avoided thereby starting the incision over the free edge of tragus which would further enhance the aesthetic appeal.

\section{Conclusion}

Patients were followed up from 6 months to 1 year and all the patients were highly satisfied with the aesthetic results achieved as no facial scar was perceptible. The incision enables satisfactory tumour exposure as well as facial nerve exposure. We encountered no significant post-operative complication. This incision can be used as an approach for other surgeries like mandibular condyle fracture reduction. Therefore, we are continuing to use the same incision for all the parotid surgeries. Largescale study will further help us to validate our results.

\section{References}

1. Donovan DT, Conley JJ. Capsular significance in parotid tumour surgery: Reality and myth of lateral lobectomy. Laryngoscope 1984; 94(3):324-9

2. Upile T, Jerjes WK, Nouraei SA, Grant W, Singh S, Sudhoff $\mathrm{H}$ et al. Further anatomical approaches to parotid surgery. Eur Arch Otorhinolaryngol. 2010; 267(5):793-800

3. Ilizuka T, Ladrach K, Geering AH, Paveh J. Open reduction without fixation of dislocated condylar process fractures: Long term clinical and radiological analysis. J Oral Maxillofac Surg. 1998; 56:553-61

4. Appiani E, Delfino MC. Plastic incision for facial and neck tumours. Ann Plast Surg. 1984;13(4):335-52

5. Roh JL.Retroauricular hairline incision for removal of upper neck masses. Laryngoscope 2005; 115(12):2161-6

6. Panda NK, Kaushal D, Verma R. Do we need to modify the parotidectomy incision? Indian J Otolaryngol Head and Neck Surg. 2016; 68(4):487-9

7. Shah J, Patel S, Singh B. Jatin Shah's Head and Neck Surgery and Oncology. 4th ed. Mosby Elsevier. Salivary glands (13)5447. 